\title{
Histiocytose à cellules de Langerhans : suivi à long terme de deux cas à localisation faciale traités par chirurgie exclusive
}

\author{
Langerhans' cells histiocytosis: long term follow up of two cases with facial \\ localization treated by exclusive surgery
}

\author{
LAURENT DEVOIZE*, MARTINE BAUDET-POMMEL*, CÉDRIC HUARD*, HÉLĖNE GOUBY*,J EAN-MICHEL MONDIÉ**
}

\begin{abstract}
RÉSUMÉ
L'histiocytose X, ainsi dénommée par Lichtenstein en 1953 [1], est maintenant désignée sous le terme d'histiocytose langerhansienne [2,3]. C'est une affection du groupe des réticuloses. Elle est caractérisée par une prolifération localisée ou disséminée de cellules dendritiques, issues des phagocytes mononucléés de la moelle osseuse (cellules ayant le phénotype de la cellule de Langerhans caractérisée, entre autres, par la présence de granules de Birbeck). Elles sont dénuées de caractères cytologiques de malignité et touchent essentiellement les organes riches en tissu réticulo-endothélial. Ces cellules, présentatrices de l'antigène au même titre que les macrophages, sont également retrouvées dans d'autres tissus périphériques comme la peau, la muqueuse vaginale, la muqueuse buccale, la trachée, le thymus, les vaisseaux sanguins et les ganglions lymphatiques. Les histiocytoses à cellules de Langerhans ont des expressions cliniques très différentes et des évolutions très variables. On distingue ainsi le granulome éosinophile (forme à localisation osseuse solitaire ou multiple), la maladie de Hand-Schüller-Christian (forme chronique et disséminée associant lésions osseuses et viscérales) et la maladie de Abt-Letterer-Siwe (forme aiguë disséminée maligne). Ces trois formes s'inscrivent dans un même cadre nosologique et, surtout, se caractérisent par un substratum histologique commun. Le traitement repose sur l'exérèse et le curetage chirurgical des lésions osseuses bien localisées. En présence de lésions plus étendues, multiples et/ou inaccessibles, le traitement varie selon les auteurs.

Nous présentons deux cas cliniques, I'un correspondant à un granulome éosinophile multifocal, l'autre à une maladie de Hand-Schüller-Christian. Ces deux cas ont été diagnostiqués, traités et suivis dans le service de Stomatologie et de Chirurgie Maxillo-Faciale de Clermont-Ferrand, sur une période de 10 ans. (Med Buccale Chir Buccale 2005 ; 11 : 159-73).

mots clés : histiocytose $X$, histiocytose à cellules de Langerhans, granulome éosinophile, maladie de HandSchüller-Christian, maladie de Abt-Letterer-Siwe, chirurgie, traitement

\section{SUMMARY}

Histiocytosis $X$, so named by Lichenstein in 1953 [1], now indicated like Langerhans' cell histiocytosis [2,3], is an affection of reticulosis' group, caracterised by local or disseminated proliferation of dendritic cells of the bone marrow (Langerhans' cells), denued of cytologic caracters of malignancie, striking wealthy organs in reticulo-endothelial tissues. Those antigen presentating cells, like macrophagus, are find too in other peripherical tissues like skin, vaginal mucosa, buccal mucosa, trachea, thymus, blood vessels and lymphatic nodes. Under his generic title, are gather, in fact, three affections, who, even if they have very different and variable clinical expressions and evolutions, enroll for the same nosologic settings, and are caracterised by the same histologic substratum. Three forms are usually described: eosinophilic granuloma (localized and chronic form), Hand-Schüller-Christian disease (disseminated and chronic form) and Abt-Letterer-Siwe disease (acute and disseminated form).
\end{abstract}

\footnotetext{
* Service d'O dontologie, Unité de Pathologie et de Thérapeutique Buccale, CHRU Clermont-Ferrand, France.
}

** Service de Stomatologie et de Chirurgie Maxillo-Faciale, CHRU Clermont-Ferrand, France. 
The surgical excision and curretage of well defined lesions is the best treatment for histiocytosis with bone localization. In most extended cases, in case of multiple or inaccessible lesions, treatments are different with schools. We present two case reports, respectively suffering for multifocal eosinophilic granuloma for the first, and HandSchüller-Christian disease for the second. Those two cases were diagnosed, treated and followed up in the department of stomatology and maxillo-facial surgery of Clermont-Ferrand during ten years. (Med Buccale Chir Buccale 2005 ; 11 : 159-73).

key words : histiocytosis X, Langerhans' cell histiocytosis, eosinophilic granuloma, Hand-Schüller-Christian disease, Abt-Letterer-Siwe disease, surgery, treatment

L'histiocytose à cellules de Langerhans est une affection qui peut toucher différents sites, allant d'une atteinte limitée (granulome éosinophile) à une affection plus diffuse, intéressant plusieurs territoires squelettiques et/ou extra-squelettiques (maladie de Hand-Schüller-Christian et maladie de Abt-Letterer-Siwe).

Historiquement, il faut remonter en 1893 pour trouver la première description [4]. Ces désordres histiocytaires, longtemps regroupés sous le terme d'histiocytose $X$, le sont maintenant sous le terme d'histiocytose à cellules de Langerhans.

Par la suite, les affections suivantes ont été successivement isolées :

- La maladie de Hand-Schüller-Christian [4-6], forme chronique et disséminée de l'histiocytose $X$, survient habituellement dans la petite enfance et se caractérise, dans sa forme typique, par l'association de lacunes osseuses crâniennes (granulome éosinophile), d'une exophtalmie et d'un diabète insipide.

- La maladie de Abt-Letterer-Siwe $[7,8]$, forme aiguë ou subaiguë, disséminée (poly-viscérale) de l'histiocytose $X$, se rencontre surtout chez le nourrisson et le très jeune enfant. Caractérisée par une infiltration diffuse des organes hématopoïétiques, des poumons, des os et de la peau, elle se manifeste par un tableau clinique sévère, marqué par une atteinte importante de l'état général et des lésions viscérales majeures et multiples. Rapidement évolutive, cette réticulose aiguë est le plus souvent fatale à brève échéance.

- Le granulome éosinophile [1], forme chronique et localisée, est aussi la forme la plus bénigne de l'histiocytose $X$. Touchant habituellement le grand enfant et l'adulte jeune, il est généralement bénin, d'extension limitée, ne concerne que l'appareil squelettique et donne des lésions ostéolytiques le plus souvent solitaires. Si pratiquement tous les os peuvent être touchés, les lésions intéressent plus fréquemment le squelette craniofacial. L'affection do it son nom à la présence de nombreux polynucléaires éosinophiles au sein du granulome histiocytaire.

La présentation de deux observations permettra de bien illustrer cette affection : I'une correspond à un granulome éosinophile multifocal, l'autre à une maladie de Hand-Schüller-Christian.

\section{OBSER VATIONS}

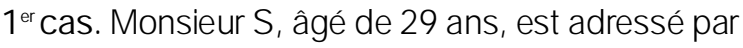
son chirurgien dentiste dans le Service de Stomatologie et de Chirurgie Maxillo-Faciale du CHU de Clermont-Ferrand pour avis et traitement. A l'examen clinique endobuccal, on découvre une communication buccosinusienne entre 13 et 15 (14 étant absente), une muqueuse d'aspect nécrotique autour de cette communication, et une mobilité de 15, 16 et 17. Sur la crête alvéolo-mandibulaire gauche, la muqueuse est bourgeonnante et ulcérée ; 35, 36 et 48 sont très mobiles, 37 et 38 ont été avulsées antérieurement. II n'y a pas de signe de Vincent, ni d'adénopathies cervico-faciales associées. L'état général est conservé et l'interrogatoire du patient ne révèle aucun antécédent particulier. Le panoramique dentaire (Fig. 1 ) révèle deux lésions : une importante alvéolyse entre 13 et 17 avec disparition du plancher sinusien, et une lacune osseuse mandibulaire gauche intéressant à la fois l'os alvéolaire et l'os 


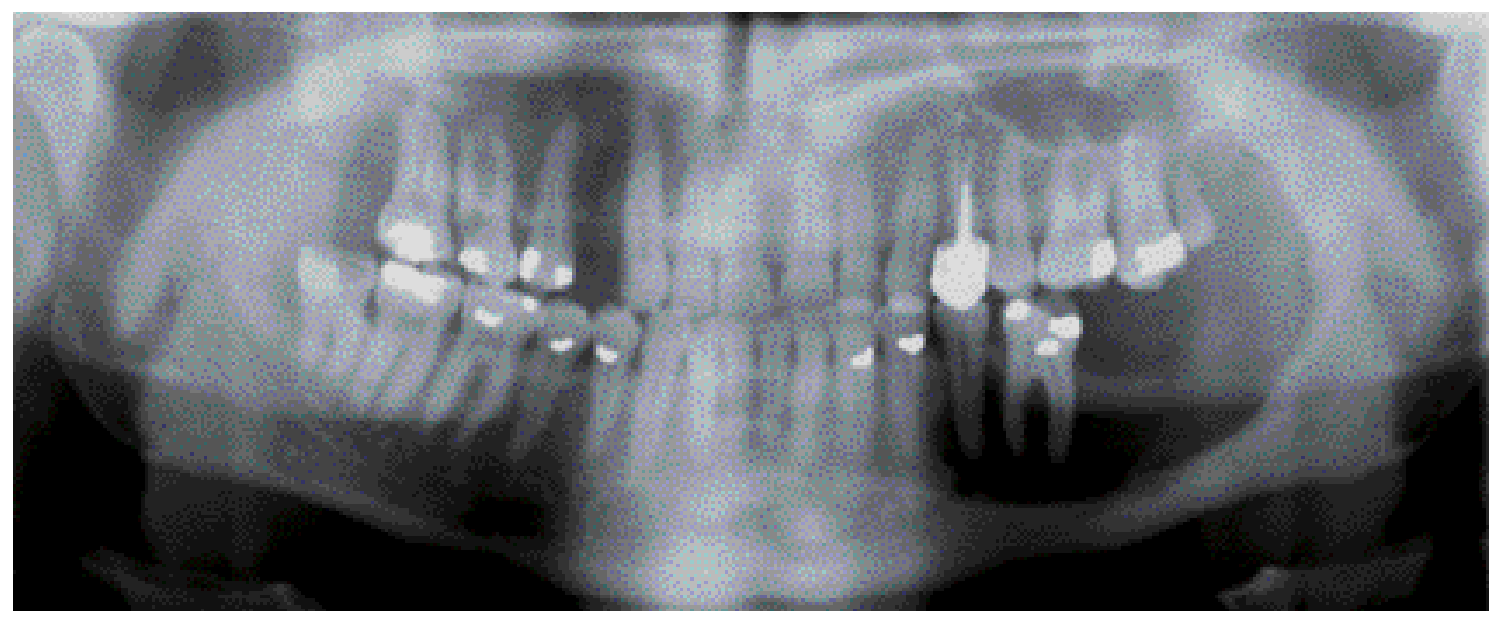

Figure 1 : Panoramique initial : lésions ostéolytiques dans la région de 13 - 17 et dans la région prémolo-molaire inférieure gauche.

Initial panoramic X-ray : osteolytic lesions in the region of 13 - 17 and in the inferior left premolar-molar region.

mandibulaire sous-jacent. Ses contours sont relativement nets, sans liseré d'ostéoc ondensation périphérique. Les dents 35 et 36 , comme suspendues au-dessus de la cavité, ne présentent pas de rhizalyse. On retro uve également une lacune osseuse d'aspect kystique dans la région distale à la 48. La confrontation des données cliniques et radiologiques amène à suspecter une histiocytose $X$.

Le bilan biologique ne montre rien de particulier, à part une légère augmentation de la vitesse de sédimentation (10 $\mathrm{mm}$ après une heure) et une protéinémie légèrement augmentée $\left(79 \mathrm{g.}^{-1}\right)$.

Une intervention à visée diagnostique est programmée avec avulsion de 36 et biopsies gingivale, alvéolaire et mandibulaire. Différents prélèvements sont envoyés en bactériologie et en anatomopathologie. Sur les coupes histologiques, on retrouve un granulome inflammatoire pars emé de quelques zones nécrotico-hémorragiques avec un infiltrat très polymorphe constitué de lymphocytes, de plasmocytes, de polynucléaires éosinophiles, et d'histiocytes dont le noyau présente par endroits une scissure centrale. Aucun élément suspect de malignité n'est observé et l'examen anatomopathologique confirme le diagnostic d'histiocytose $X$.

Un bilan d'extension est alors entrepris afin d'apprécier le degré de dissémination de l'affection, de permettre la classification de ces lésions dans le cadre de l'histiocytose $X$ et de déterminer le traitement à proposer. Les résultats sont les suivants :
- La scintigraphie du squelette entier ne montre pas d'autres zones d'hyperfixation de l'isotope que celles présentes dans le maxillaire et la mandibule (Fig. 2).

- La radiographie pulmonaire et les explorations fonctionnelles respiratoires révèlent une pneumopathie interstitielle sans retentissement fonc-

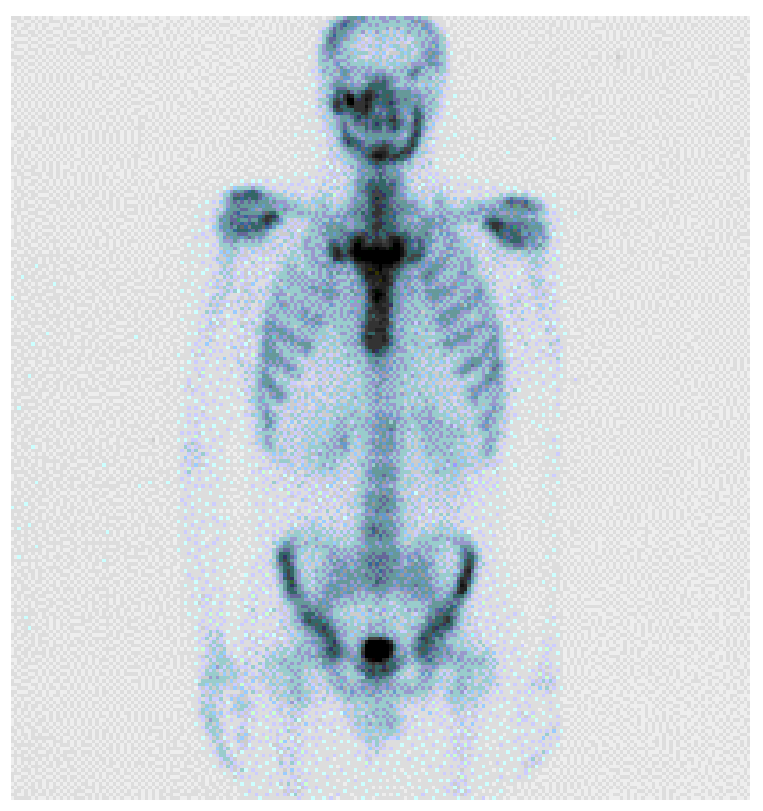

Figure 2 : Scintigraphie du squelette entier montrant que les lésions faciales sont isolées.

Whole body scintigraphy showing that the lesions of the face are isolated. médecin€ buccale chirurgie buccale VOL. $11, \mathrm{~N}$ 2005 page 161 
tionnel. La fibroscopie bronchique avec lavage alvéolaire et la biopsie pulmonaire permettent de confirmer le diagnostic d'histiocytose $X$ sans signe de malignité.

- Le bilan hépatique est normal.

- L'examen tomodensitométrique du massif facial et de la mandibule en fenêtres osseuse et parenchymateuse après injection de gadolinium confirme l'extension exacte des lésions (Fig. 3-5).

Au terme du bilan, il s'agit d'une forme essentiellement osseuse, avec une triple localisation faciale, assimilable à un granulome éosinophile multifocal. Le traitement comporte l'exérèse chirurgicale des lésions par voie endobuccale : énucléation des tumeurs et curetage des cavités. Celle du maxillaire est particulièrement importante du fait de la destruction subtotale du malaire. Le plancher et la paroi antérieure du sinus maxillaire jusqu'à la fosse nasale droite, le rebord orbitaire inférieur et les lames pala-

médecine buccale chirurgie buccale

L. $11, \mathrm{~N}^{\circ} 3$ 2005 page 162
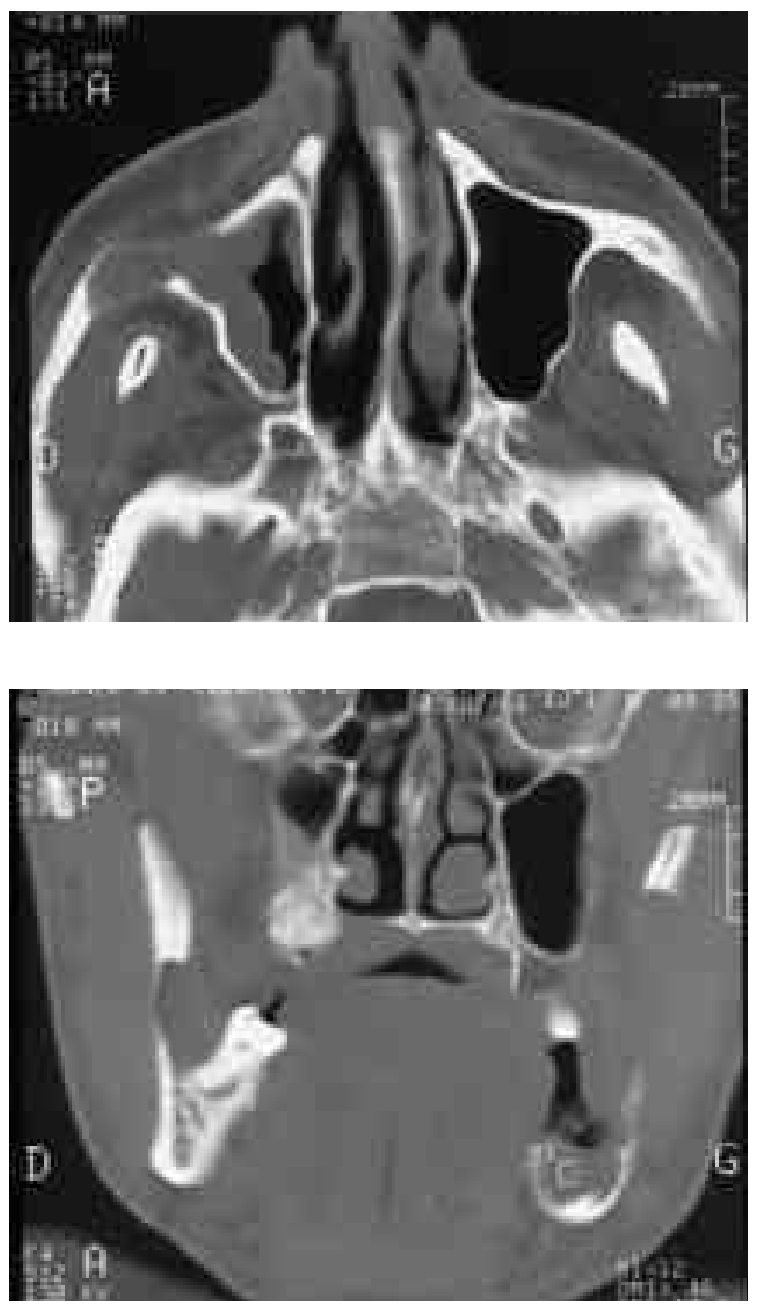

tines du maxillaire droit sont également atteints. Les dents 15, 16, 17, 33, 34, 35 et 48 sont alvulsées. Le nerf alvéolaire inférieur gauche est réséqué lors du traitement des lésions mandibulaires.

L'examen anato mopathologique confirme le diagnostic initial avec présence à l'immunomarquage, sur les éléments inflammatoires, des protéines membranaires MT1, de la protéine $S 100$ et de quelques éléments résiduels de CD 68 .

Deux mois après l'intervention, les deux lésions mandibulaires semblent complètement cicatrisées. Au maxillaire, dans le fond du vestibule, il persiste une communic ation buccosinusienne qui n'est pas traitée immédiatement car elle permet de surveiller l'apparition d'une éventuelle récidive dans le sinus. Lors du contrôle postopératoire après deux ans, la radiographie montre une image suspecte dans la région distale à la 47 , faisant craindre une poursuite évolutive de la maladie (Fig. 6). Un nouveau

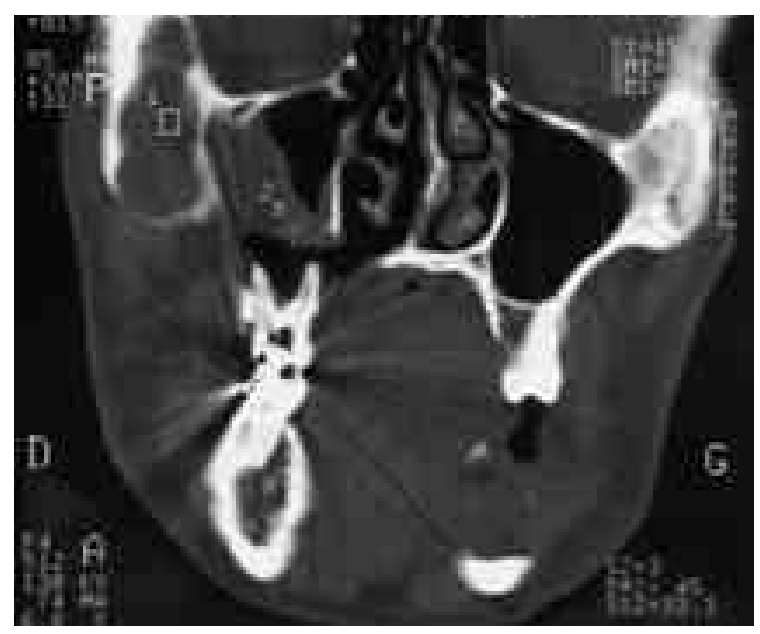

Figures 3-4-5 : Examen tomodensitométrique du massif facial pour évaluer l'extension des lésions. Notez l'atteinte du sinus maxillaire et du malaire droit. Tomodensitometry examination of the face to evaluate the extension of the lesions. Note the involvement of the maxillary sinus and right zygomatic bone. 


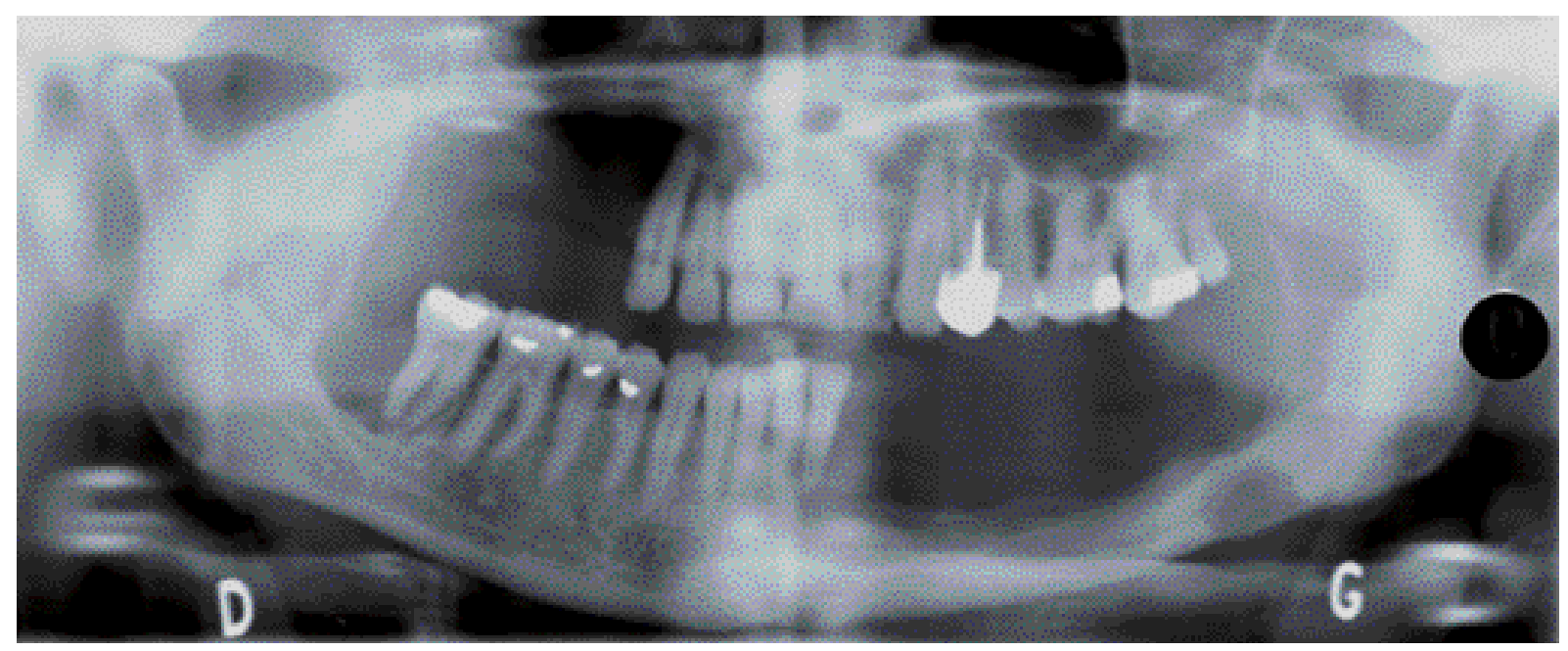

Figure 6 : Panoramique de contrôle deux ans après la première intervention. $\mathrm{P}$ anoramic $\mathrm{X}$-ray at the check-up two years after the first operation.

curetage de la lésion et l'avulsion de 47 sont réalisés. L'examen anatomopathologique confirme qu'il s'agit d'une récidive.

Lors du contrôle suivant, l'examen endobuccal met en évidence une mobilité anormale du bloc incisivocanin mandibulaire. Le panoramique dentaire objective une nouvelle localisation dans la région symphysaire englobant les apex des quatre incisives (Fig. 7). Un nouveau curetage est réalisé avec avulsion des quatre incisives mandibulaires et, dans le même temps, fermeture de la communication bucco-sinusienne résiduelle.
Deux ans plus tard, alors que l'évolution semble se faire vers la stabilisation des lésions, l'apparition d'une tuméfaction génienne droite amène le patient à consulter. L'antibiothérapie entraîne une régression de la tuméfaction, mais l'examen radiologique montre, entre les deux prémolaires mandibulaires restantes (44 et 45 ), une nouvelle localisation de l'histiocytose, nécessitant de réintervenir chirurgicalement (Fig. 8). La zone tumorale est excisée dans sa totalité avec avulsion de $43,44,45$ et 46 et résection du nerf alvéolaire inférieur.

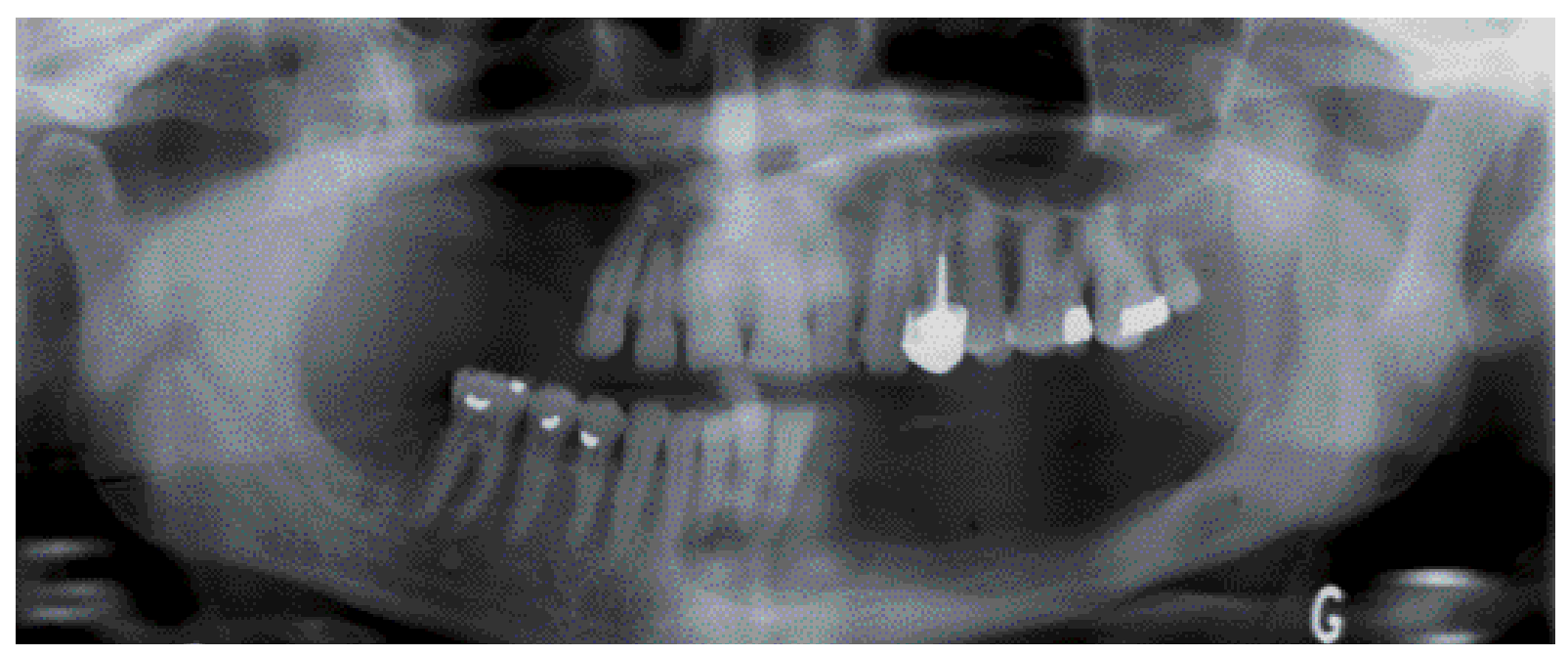

Figure 7 : Nouvelle localisation dans la région symphysaire. New localisation in the symphyseal region. 


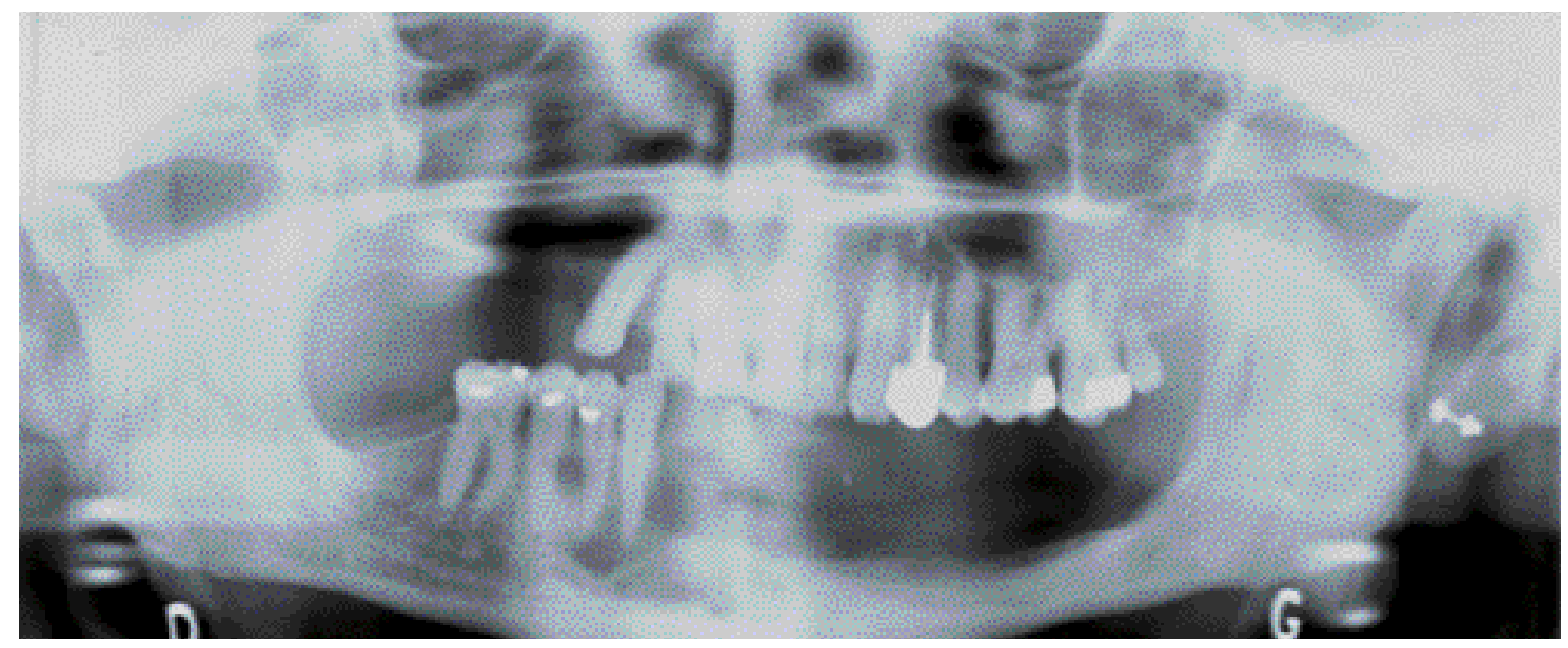

Figure 8 : Découverte d'une nouvelle localisation entre 44 et 45. Discovery of a new localisation between 44 and 45 .

médecine buccale chirurgie buccale

L. $11, \mathrm{~N}^{\circ} 3$ 2005

page 164

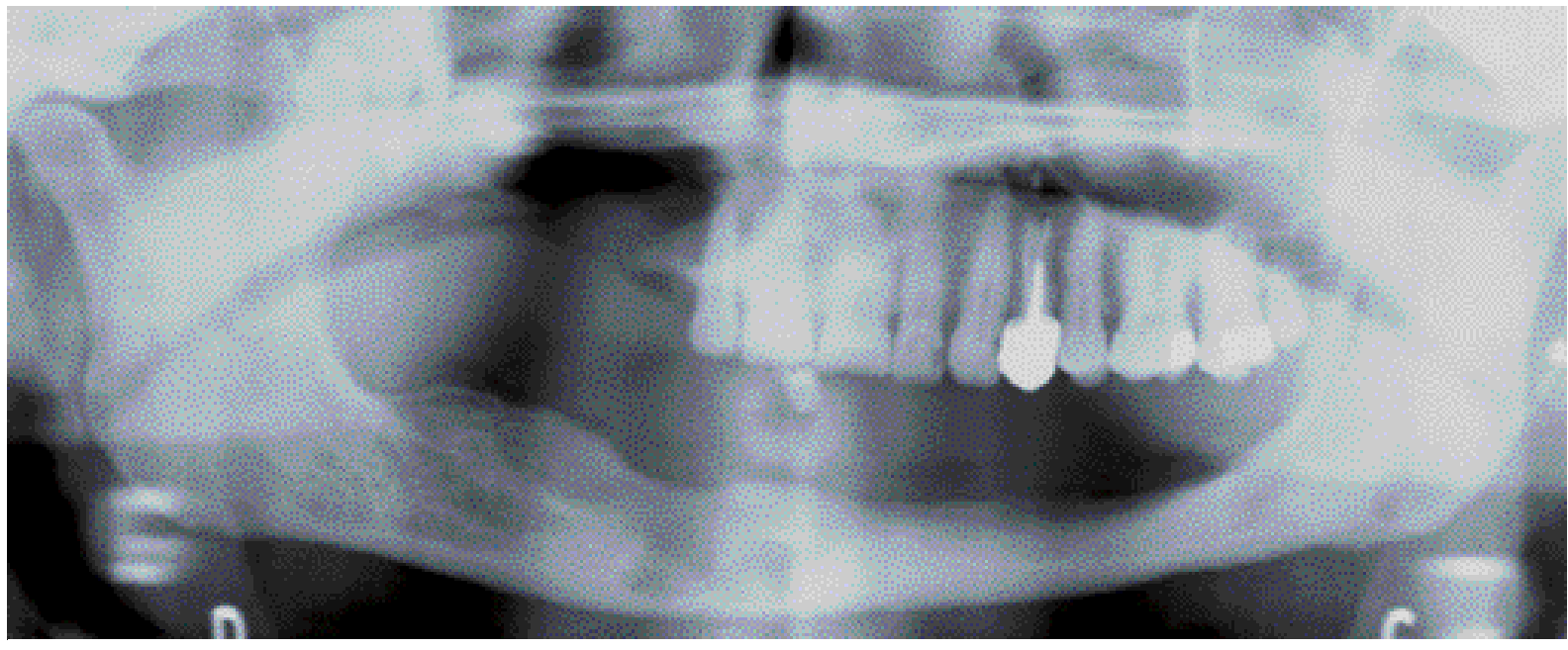

Figure 9 : Récidive dans la région parasymphysaire droite. Recurrence in the right parasymphyseal region.

Sept ans après la première consultation, l'apparition de douleurs maxillaires et mandibulaires conduit le patient à consulter. L'examen tomodensitométrique met en évidence une nouvelle lésion parasymphysaire droite, et une autre maxillaire intéressant 3 des 4 incisives (Fig. 9). L'exérèse totale de la lésion maxillaire est réalisée.

$2^{\mathbf{e}}$ cas. M lle B, âgée de 23 ans, consulte son chirurgien dentiste pour une légère mobilité de 46 et 47, accompagnée de douleurs lancinantes et conti- nues, irradiant vers l'oreille. Devant cette symptomatologie, il suspecte un accident infectieux en rapport avec 48 qui est extraite et il met en place une contention intercoronaire entre 46 et 47 . La patiente ne se présente pas au rendez-vous de contrôle et elle ne revient consulter que 10 mois plus tard. II existe une augmentation de la mobilité de 46 et 47 , I'apparition d'une mobilité dentaire intéressant 33 et 34 , et une absence de cicatrisation de l'alvéole de 48. Ces signes d'ostéolyse évolutive font adresser la patiente à un stomatologue qui évoque d'emblée 
une pathologie de type histiocytose $X$ devant cette symptomatologie et la découverte à l'anamnèse d'un diabète insipide traité depuis tro is ans par desmopressine (Minirin $\left.{ }^{\circledR}\right)$. La patiente est alors dirigée vers le Service de Stomatologie et de Chirurgie Maxillo-Faciale du CHU de Clermont-Ferrand pour une prise en charge. L'examen clinique confirme la présence des lésions maxillaires. Une légère dysesthésie labiomentonnière inférieure droite est apparue entre temps. Aucune adénopathie cervicale n'est décelée, l'état général est conservé. Le panoramique dentaire montre deux images ostéolytiques mandibulaires. La première, parasymphysaire gauche, en forme de panier arrondi, va des collets de 32 à 35. Elle détruit tout l'os alvéolaire et s'étend jusqu'à l'os basilaire. Les dents semblent être suspendues au-dessus de la cavité ostéolytique. La seconde, angulaire droite, polycyclique, se prolonge vers le coroné et la branche horizontale. Elle touche les racines de $44,45,46$ et $47 ; 46$ et 47 semblent également «flotter dans le vide » (Fig. 10).

Pour évaluer l'extension exacte des lésions et dépister d'éventuelles lésions à un stade initial, des incidences complémentaires et un examen tomodensi-

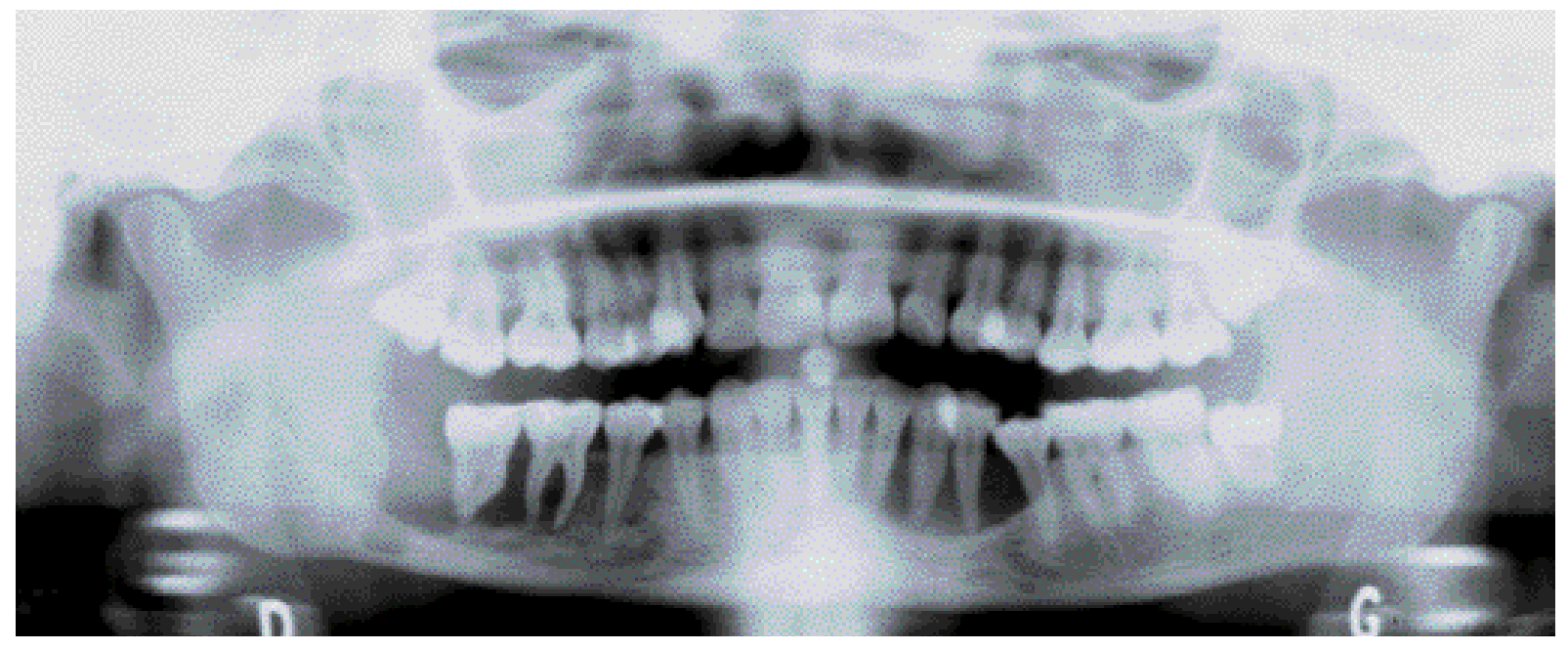

médecin€ buccale chirurgie buccale

VOL. $11, \mathrm{~N}$ 2005

page 165

Figure 10 : Panoramique réalisé lors de la première consultation Panoramic X-ray taken at the first visit.
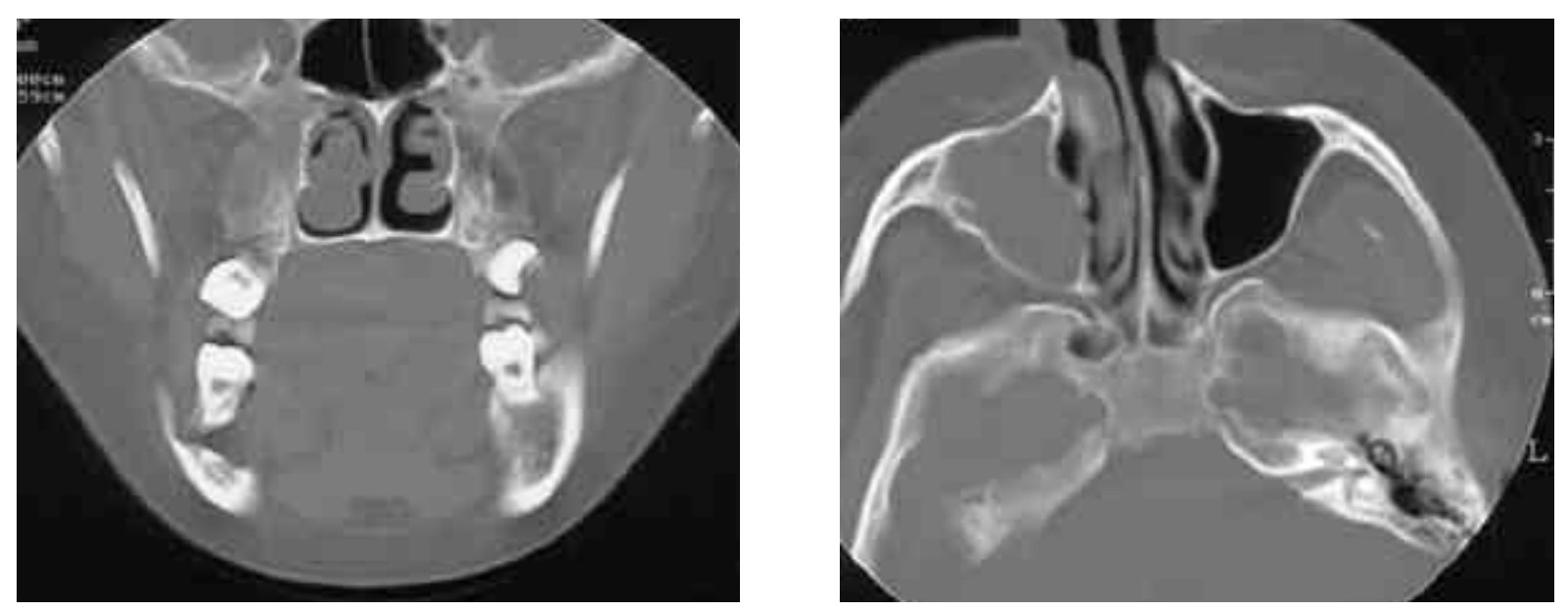

Figures 11-12 : Examen tomodensitométrique confirmant les deux lésions ostéolytiques mandibulaires et l'opacité du sinus maxillaire droit. Tomodensitometry examination confirming the two osteolytic lesions of the mandible and the opacity of the right maxillary sinus. 
médecine buccale chirurgie buccale

page 166 tométrique crâniofacial sont réalisés. Ces examens confirment que les deux lésions mandibulaires s'étendent dans les tissus mous environnants et montrent une opacité du sinus maxillaire droit, qui semble s'inscrire dans le cadre de cette pathologie. Les données radiographiques et le tableau clinique avec présence d'un diabète insipide orientent vers le diagnostic de maladie de Hand-Schüller-Christian. Dans le même temps chirurgical, on réalise l'exérèse des deux lésions, l'avulsion des dents en rapport avec ces deux lésions (c'est-à-dire 31, 32, 33, $34,45,46$ et 47 ), puis le curetage des cavités avec conservation du nerf alvéolaire inférieur droit. L'ouverture de la paroi antérieure du sinus maxillaire permet d'énucléer une lésion kystique, macroscopiquement différente des deux autres lésions, et de faire un curetage méticuleux du sinus ; un ballonnet hémostatique est laissé en place. Les dents situées en regard de la lésion sinusienne sont conservées. Les différents prélèvements sont envoyés en anatomopathologie. La lésion parasymphysaire gauche est constituée d'un tissu de granulation richement vascularisé, hémorragique, inflammatoire, infiltré par des lymphocytes, des plasmocytes, de nombreux polynucléaires éosinophiles et quelques cellules de Langerhans. La lésion mandibulaire droite présente le même aspect : elle est constituée par un tissu de granulation œdémateux, congestif avec des zones d'infiltration hémorragique, de nombreux éléments inflammatoires mono- et polynucléés ainsi que par des cellules de Langerhans typiques. L'examen de la paroi du kyste sinusien droit montre qu'ils'agit d'une muqueuse sinusienne, très inflammatoire, richement vascularisée, hémorragique avec des éléments cellulaires mono- et polynucléés. Toutes ces lésions correspondent à des lésions d'histiocytose $X$; les immunomarquages par la protéine $S 100$ et le CD1 sont positifs.

Un bilan d'extension est pratiqué. II comporte :

- Une scintigraphie osseuse du squelette entier qui montre un foyer d'hyperfixation intense et diffus dans la mandibule et un autre dans le maxillaire droit, correspondant aux lésions opérées. Elle permet d'objectiver un petit foyer dans la région sousorbitaire droite. Sur le reste du squelette, on ne retrouve aucun foyer.

- Une radiographie pulmonaire qui met en évidence un fin semis réticulonodulaire. Bien que la patiente soit totalement asymptomatique sur le plan respiratoire, cet aspect fait pratiquer un examen tomodensitométrique thoracique qui révèle une diminution de transparence du parenchyme pulmonaire (aspect de verre dépoli diffus mais difficile à interpréter en raison de la présence d'artefacts).

- Un examen tomodensitométrique abdominal qui est normal.

- Une biopsie rénale, également normale.

- Quelques investigations immunologiques sont réalisées : le taux des anticorps anti-nucléaires et du complément, et la sérologie rhumatoïde sont normaux.

Au terme de ce bilan, il ressort que cette patiente présente une histiocytose langerhansienne multifocale avec diabète insipide, assimilable à une maladie de Hand-Schüller-Christian. Pour cette patiente, I'affection se manifeste essentiellement par une atteinte osseuse mandibulaire et probablement sous-orbitaire, et par une atteinte pulmonaire mineure. En l'absence de symptomatologie respiratoire, il n'a pas été jugé nécessaire d'instaurer un traitement supplémentaire, par exemple une corticothérapie, tout en sachant que l'apparition d'un nouvel élément, voire l'aggravation de la pathologie déjà existante, motiverait un bilan complet et ferait rediscuter les indications thérapeutiques. Le traitement du diabète insipide est poursuivi.

Deux mois après l'intervention, les trois sites apparaissent complètement cicatrisés (Fig. 13). L'anesthésie labiale inférieure dro ite, liée au curetage de la tumeur, persiste. Aucune autre mobilité dentaire n'est observée. La patiente souhaitant une réhabilitation dentaire rapide, elle est adressée au centre de soins dentaires du CHU de Clermont-Ferrand. Au cours des six mois qui suivent, on assiste peu à peu à la récupération de la sensibilité labiomentonnière droite, puis à la réossific ation des deux lacunes mandibulaires. L'opacité du sinus maxillaire droit s'est atténuée progressivement, mais elle est encore présente ; les parois du sinus apparaissent normales (Fig. 14). Alors que l'évolution semble se faire favorablement, un panoramique dentaire de contrôle découvre une nouvelle lésion à l'aplomb de la 38, sous forme d'une image radioclaire ovoïde, taillée à l'emporte-pièce, au centre de la mandibule et atteignant le rebord basilaire. La réossification des deux lacunes mandibulaires est presque complète (Fig. 15). 


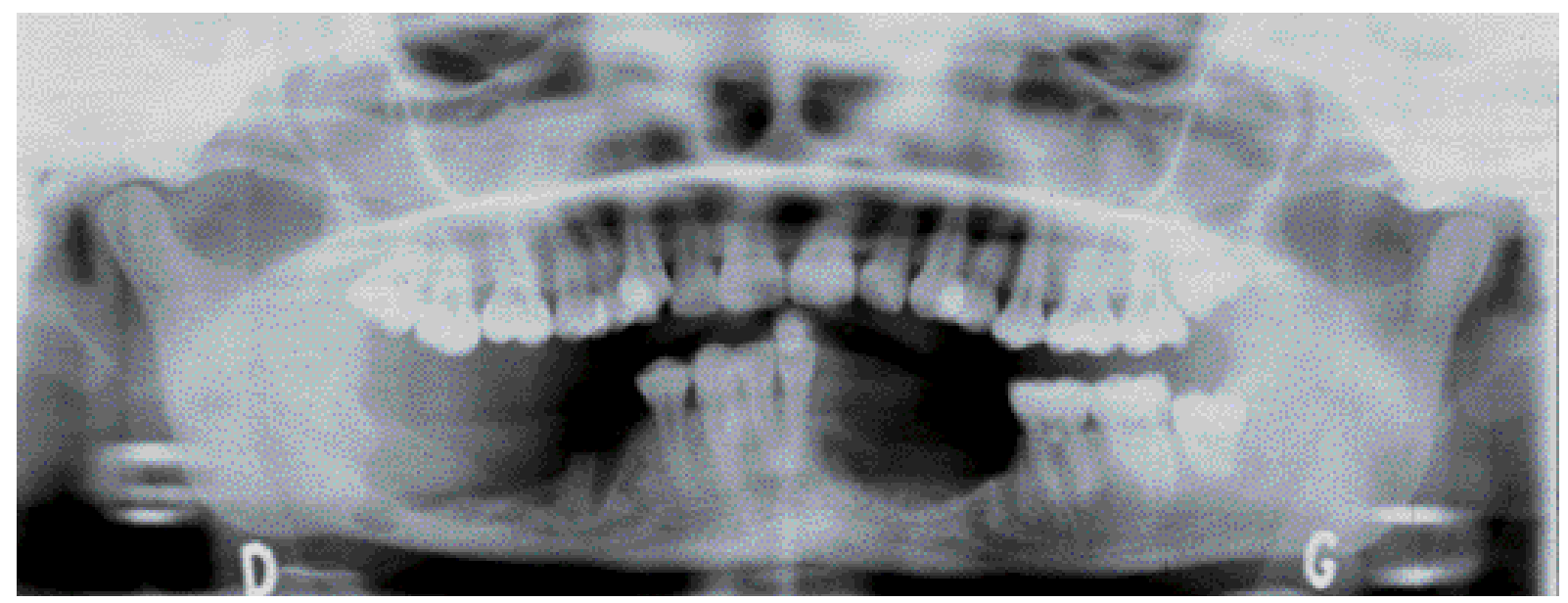

Figure 13 : Contrôle radiologique deux mois après la première intervention. Radiographic check-up two months after the first operation.

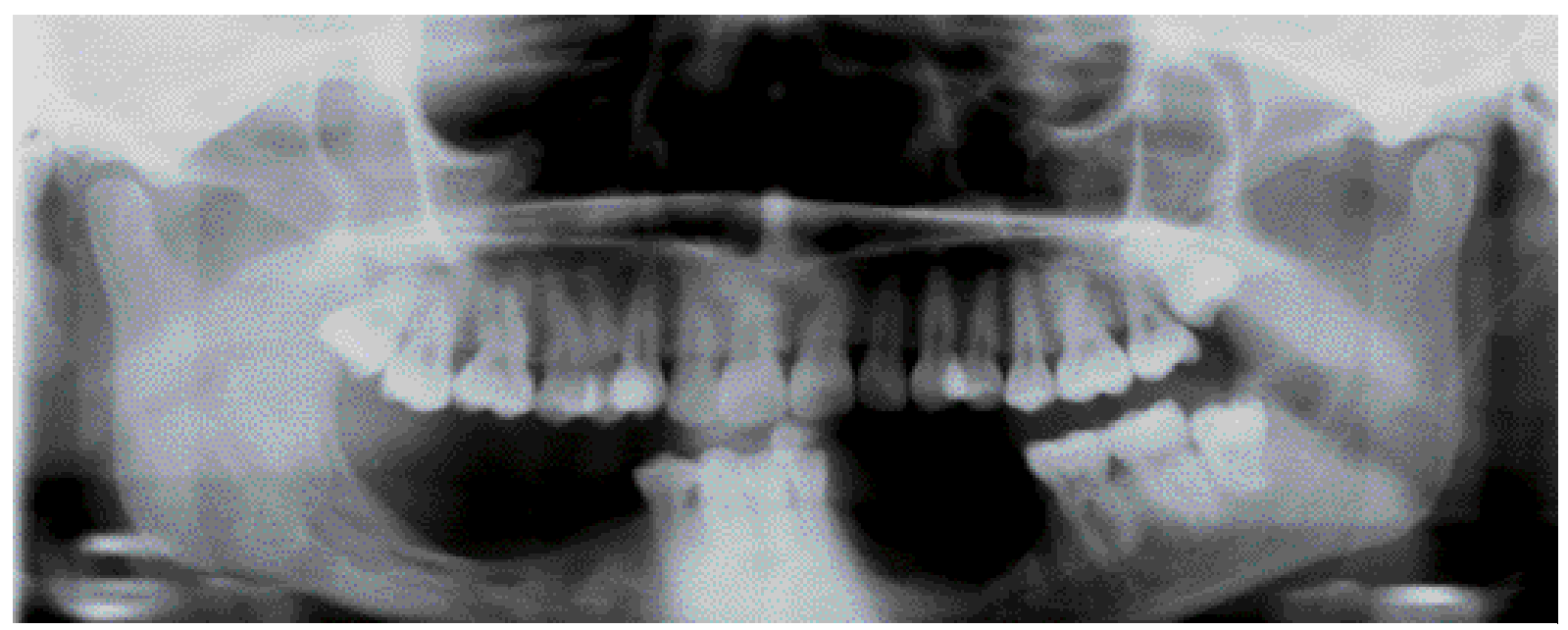

Figure 14 : Contrôle radiologique six mois après la première intervention Radiographic check-up six months after the first operation.

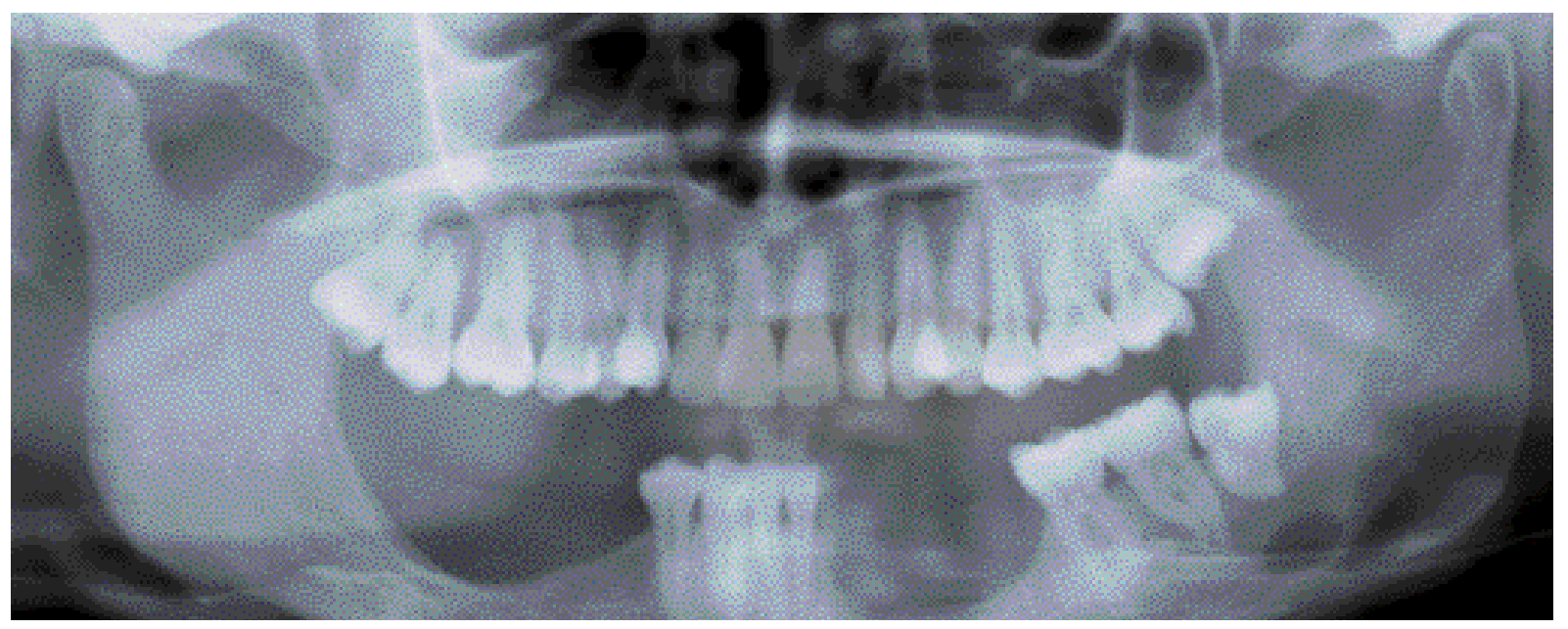

Figure 15 : Découverte d'une nouvelle localisation à l'aplomb de 38. Discovery of a new localisation directly above 38 . 


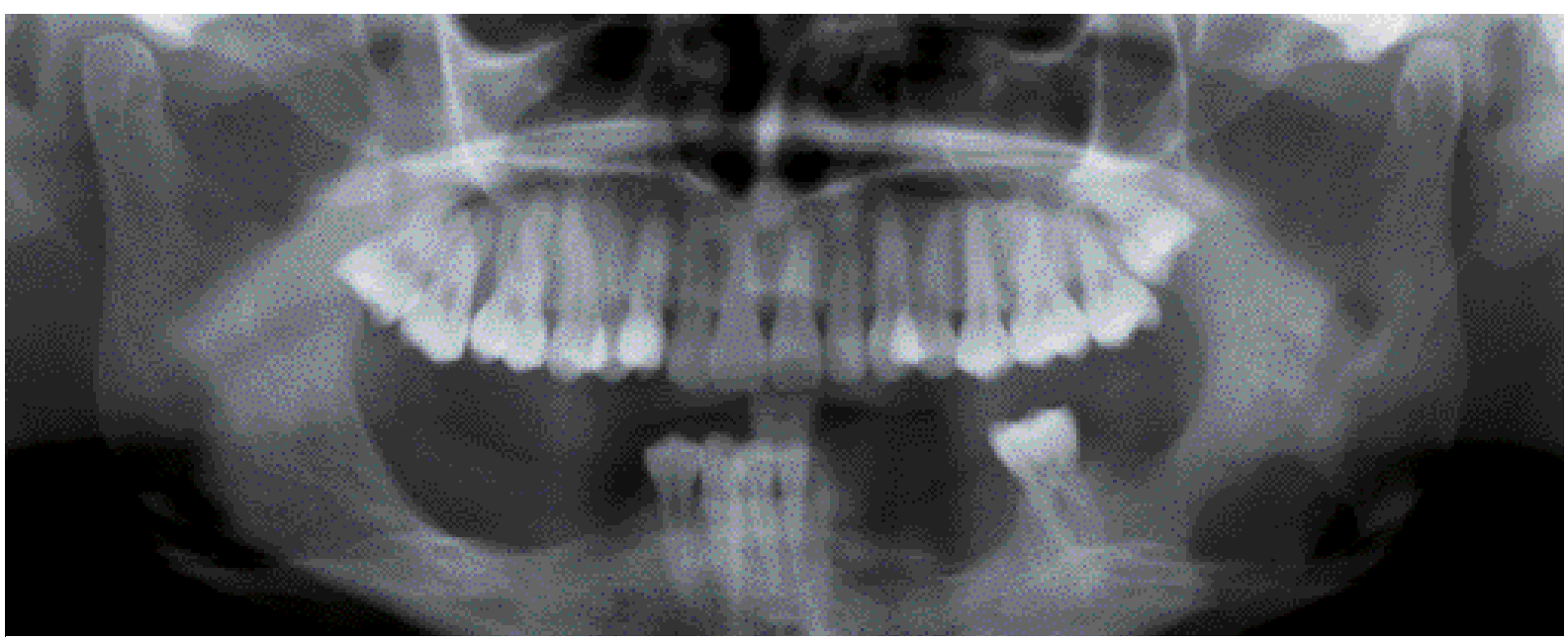

Figure 16 : Contrôle post-opératoire immédiat. Immediate post-operative check-up.

Lors de l'abord chirurgical de la lésion, on découvre une lyse complète des corticales mandibulaires interne et externe, et une lyse importante du rebord basilaire ; 37 et 38 sont extraites. L'énucléation de la tumeur est accompagnée d'un curetage soigneux de la cavité (Fig. 16). L'examen anatomopathologique confirme qu'il s'agit bien d'une lésion d'histiocytose $X$. Les suites opératoires sont simples et la cicatrisation du site semble satisfaisante. Même s'il n'y a pas eu de nouvelles lésions depuis, la surveillance est poursuivie. En l'absence de symptomatologie, une radiographie pulmonaire, une exploration fonctionnelle respiratoire et un bilan inflammatoire sont réalisés systématiquement tous les ans.

\section{COMMENTAIRES}

L'histiocytose $X$ est une affection rare, sporadique, qui ne semble répondre à aucun caractère génétique, racial ou géographique particulier et qui survient en dehors de tout contexte socioculturel. L'incidence de cette affection, d'après Broadbent $[9]$, serait de 1 cas pour 2 millions. Il existe une prédominance nette pour le sexe masculin, le sexe ratio variant de 4 à 5 pour 1 [10]. Elle peut s'observer à tout âge. Cependant, elle reste avant tout une maladie du sujet jeune puisqu'elle survient dans $50 \%$ des cas avant 20 ans et devient exceptionnelle après 40 ans. L'âge des patients va de 2 semaines à 53 ans [10], avec un maximum de fréquence se situant entre 25 et 30 ans [11].
D'après Hartman [12], $78 \%$ des cas correspondent à un granulome éosinophile $(53 \%$ ayant une localisation unique, $25 \%$ ayant des localisations multip les) et s'observent surtout chez l'adolescent et l'adulte jeune. La maladie de Abt-LettererSiwe se rencontre essentiellement chez le nourrisson avant 18 mois et représente $10 \%$ des histiocytoses. La maladie de Hand-SchüllerChristian s'observe classiquement entre 3 et $15 a n s$ et représente $12 \%$ des histiocytoses.

Environ $50 \%$ de toutes les lésions osseuses trouvées dans les histiocytoses à cellules de Langerhans touchent les os du crâne et de la face $[13,14]$. La mandibule est plus souvent atteinte que le maxillaire $[15,16]$, surtout chez les patients ayant plus de 20 ans $[17,18]$.

Lors d'une atteinte buccale, l'apparition d'une tuméfaction accompagnée de douleurs constitue le signe d'appel observé dans plus de $50 \%$ des cas [19]. On peut également retrouver par ordre décroissant :

- une parodontite agressive entraînant des migrations dentaires $(51,2 \%)$, des résorptions radiculaires $(17,1 \%)$ ou la perte de dents [20,21],

- des ulcérations ou la mauvaise cicatrisation d'un site d'extraction,

- une forte halitose,

- des hémorragies gingivales spontanées,

- des paresthésies labiales inférieures ou un signe de Vincent [22], 
- une asymétrie faciale provoquée par l'extension d'une lésion [23,24],

- une limitation de l'ouverture buccale.

Radiologiquement, ces lésions peuvent faire évoquer [25]:

- un kyste radiculodentaire devant une petite lacune sphérique ou ovoïde à l'aplomb d'une dent nécrosée ;

- une ostéite des maxillaires devant une image polycyclique dont les limites sont floues et l'aspect mité ;

- une tumeur odontogénique (un améloblastome, un myxome ou un fibrome odontogénique) ou non odontogénique (un kératokyste ou un granulome central à cellules géantes) devant une image mono- ou polygéodique ayant un aspect en «bulles de savon » ou en «rayons de miel »;

- une malformation vasculaire, en particulier un angiome, devant des lacunes ou des pseudogéodes aréolaires, de taille et de tonalité inégales, ayant un aspect en «nids d'abeille » ou en «bulles de savon » [26] ;

- une tumeur maligne (un carcinome ou un sarcome) devant une image ostéolytique à bords floconneux ou taillée à l'emporte-pièce.

Le diagnostic positif repose sur l'examen anatomopathologique. Les biopsies ou les énucléations chirurgicales montrent macroscopiquement une masse de tissu marron [25] (Fig. 17). Quels que soient le tableau clinique rencontré et les localisations observées (peau, os, poumon...), les lésions sont constituées par une prolifération de

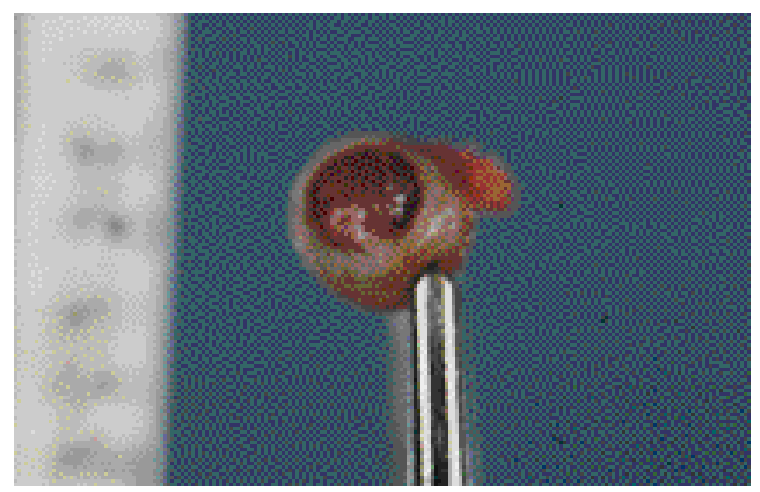

Figure 17 : Pièce opératoire constituée macroscopiquement par une masse de tissu marron.

Operative specimen represented macroscopically of a mass of brown tissue. cellules histiocytaires comportant souvent une infiltration de polynucléaires éosinophiles. La prolifération histiocytaire est plus ou moins invasive mais reste le signe prédo minant et caractéristique de toutes les lésions d'histiocytose $X$. Ils sont disposés en nappe, souvent périvasculaires, tantôt nombreux, représentant 70 à $80 \%$ de la population cellulaire, tantôt clairsemés et plus ou moins masqués par le granulome. Morphologiquement, ils se présentent comme des cellules d'un diamètre supérieur à $15 \mu \mathrm{m}$ avec un cytoplasme volumineux, finement granuleux et éosinophile. Leur noyau est large, ovoïde, incisuré, à chromatine claire, avec un ou deux nucléoles généralement visibles, parfois ronds et très chromophiles [27].

Les granules de Birbeck constituent des éléments caractéristiques des cellules de Langerhans (Fig. 18 et 19). Leur description a été faite en 1961 par Birbeck et coll. [29] dans une étude ultrastructurale portant sur les mélanocytes et les cellules de Langerhans dans le vitiligo : ils décrivent des granules intracytoplasmiques en forme de raquette avec un aspect en fermeture éclair. En 1966, Basset et coll. [30] qui publient une étude ultrastructurale sur des granulomes éosinophiles, signalent que les cellules lésionnelles contiennent des granules identiques. En 1983, Risdall et coll. [3] proposent de remplacer le terme d'histiocytose par celui de granulomatose à cellules de Langerhans.

L'étude immunohistochimique montre un marquage spécifique de I'histiocytose $X$. On utilise les anticorps monoclonaux suivants :

- OKla, spécifique de l'antigène HLA DR.

- OKT6, qui révèle un antigène commun aux thymocytes matures et aux cellules de Langerhans. Les auteurs sont en effet unanimes pour considérer que les antigènes membranaires OKT6 et HLA DR sont caractéristiques de l'histiocyte.

- la protéine $S 100$, présente dans le noyau et le cytoplasme de 80 à $95 \%$ des cellules du granulome. Bien qu'elle ne soit pas spécifique, car elle est retrouvée dans de nombreux tissus sains ou tumoraux, elle s'avère un marqueur très utile pour l'histiocytose $X$.

- I'antigène Ki-67, qui représente un bon marqueur du degré de prolifération du granulome [31]. médecin€ buccale chirurgie buccale VOL. $11, \mathrm{~N}$ 2005 page 169 


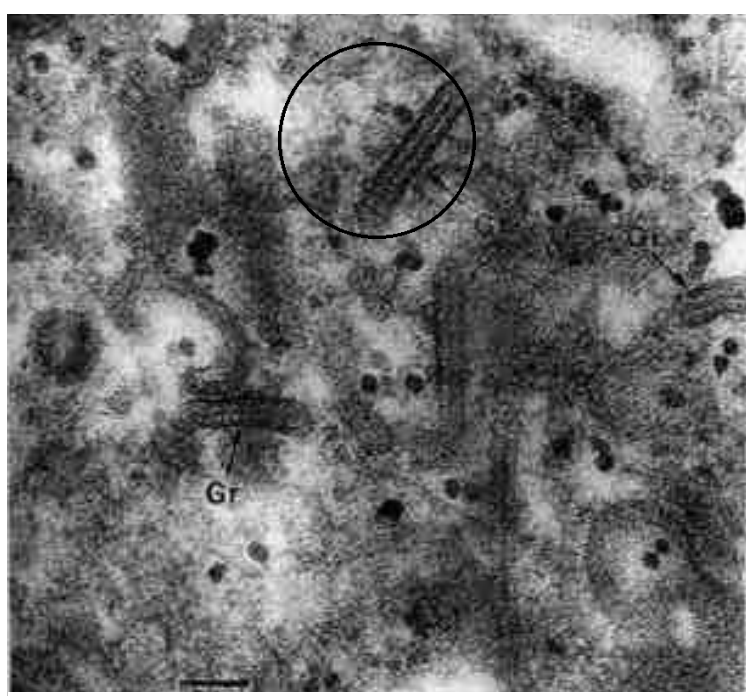

Figure 18 :Granules de Birbeck en microscopie électronique (X 83000) (d'après Dadoune et coll. [28] Electron microscope study of Birbeck granules (X 83000) (according to Dadoune et coll. [28])

médecine buccale chirurgie buccale

L. $11, \mathrm{~N}^{\circ} 3$

2005

page 170
L'ignorance du mécanisme étiopathogénique de I'histiocytose $X$ a jusqu'à présent empêché le développement d'un traitement rationnel. Actuellement, les moyens thérapeutiques demeurent nombreux et divers : chirurgie, radiothérapie, chimiothérapie, corticothérapie, abstention thérapeutique ou, plus récemment, utilisation d'extraits thymiques [35].

Il en résulte pour le clinicien un choix thérapeutique difficile qui dépend ra essentiellement des deux principaux facteurs pronostiques :

- Le degré de diffusion et le site des lésions.

- L'âge du patient, sachant que plus le patient est jeune, plus le risque de diffusion de la maladie est important.

La décision de l'abstention thérapeutique s'appuie sur l'éventualité d'une régression spontanée des lésions [32]. Si une telle attitude paraît pour certains justifiée pour les lésions isolées des maxillaires, elle reste néanmoins très discutable si l'on considère le risque d'extension de cette maladie. Une surveillance extrêmement rigoureuse s'impose.

La chirurgie doit être considérée comme le traitement de première intention surtout pour les lésions uniques, peu étendues et facilement accessibles, comme celles des maxillaires. C'est

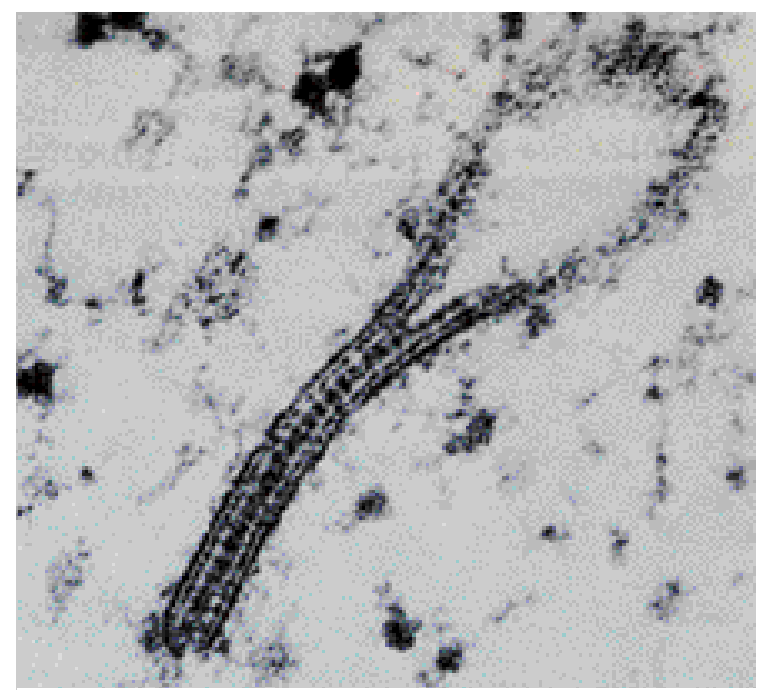

Figure 19 : Granules de Birbeck en microscopie électronique (X 100000) (d'après Chomette et coll. [10]) Electron microscope study of Birbeck granules (X 100000) (according to Chomette et coll. [10])

donc le traitement de choix du granulome éosinophile des maxillaires. L'approche chirurgicale des lésions $d$ 'histiocytose $X$ offre de multiples avantages car elle associe :

- Un geste diagnostique, en permettant l'analyse anatomopathologique du tissu prélevé.

- Un geste thérapeutique, à la fois curatif, car en éliminant le tissu pathologique, il permet de stop per le processus de destruction et favorise la reconstruction, et antalgique car il calme les douleurs.

L'intervention chirurgicale est adaptée à la taille des lésions : simple énucléation de la lésion ou résection plus ou moins étendue, emportant ou non les dents. Le curetage doit être large, englobant le tissu pathologique et le tissu sain périphérique car les limites du tissu granulomateux sont rarement nettes. L'exérèse des lésions entraîne une perte de substance, qui nécessite des mesures adaptées:

- Pour les cavités de taille réduite, une simple suture de la muqueuse suffit.

- Pour les lacunes chirurgicales étendues, la réalisation d'une greffe osseuse (greffon libre ou vascularisé) peut être nécessaire.

- Lorsqu'il y a une solution de continuité osseuse, on réalise une reconstruction avec un greffon 
libre ou un greffon vasucularisé, selon la taille du greffon.

La radiothérapie, utilisée de façon exclusive ou en complément de la chirurgie ou de la chimiothérapie, est à proscrire pour le traitement de l'histiocytose $X$.

La cortic othérapie par voie générale (prednisolone $100 \mathrm{mg}^{-1} \mathrm{j}^{-1} .13$ semaines en moyenne) est utilisée dans les formes disséminées et évolutives de l'histiocytose X. Son efficacité est relative : elle entraîne une régression des symptômes et permet une stabilisation, voire une régression temporaire des lésions. Certains auteurs ont même observé des guérisons [25].

Si la chirurgie a une action locale sur les lésions cliniquement apparentes, la chimiothérapie permet d'atteindre l'ensemble des cellules tumorales. Il sera ainsi possible de contrôler efficacement la progression de la maladie et de prévenir le développement de lésions infracliniques. La chimiothérapie est réservée aux formes sévères, diffuses et évolutives de I'histiocytose $X$, présentant des localisations multiples et des lésions difficilement accessibles à la chirurgie. II n'existe pas de protocole standard, mais l'administration d'étoposide (Etopophos $\left.{ }^{\circledR}\right)\left(150 \mathrm{mg}^{-2} \mathrm{~m}^{-2} \cdot \mathrm{sem}^{-1} \times 24 \mathrm{sem}\right)$ ou de vinblastine (Velbé $\left.{ }^{\circledR}\right)\left(6 \mathrm{mg}^{-\mathrm{m}^{-2}} \cdot \mathrm{sem}^{-1} \times 24 \mathrm{sem}\right)$ en association avec des corticoïdes semblent donner les meilleurs résultats en terme de pronostic et de toxicité [33,34]. Utilisée seule ou en association avec la chirurgie et/ou la corticothérapie, la chimiothérapie a fait la preuve d'une réelle efficacité et a permis de transformer le pronostic des formes diffuses et sévères de la maladie.

La découverte par Osband et coll. [35] d'anomalies immunologiques intéressant les lymphocytes $T$ chez des patients atteints d'histiocytose $X$, fait envisager de nouvelles perspectives thérapeutiques. Ces auteurs ont étudié les effets des extraits thymiques dans le traitement de l'histiocytose $X$. Après des résultats prometteurs sur un nombre limité de cas, ce traitement a été abandonné car il est désormais interdit d'utiliser des produits d'origine animale.

L'évolution de I'histiocytoses $X$, toutes formes confondues, est extrêmement variable. Il est donc difficile d'établir un pronostic. Les observations rapportées dans la littérature, l'existence de nom- breuses formes de passage, la survenue de certains évènements après l'épisode initial ou encore la généralisation imprévisible de certaines formes, témoignent de la difficulté d'établir un pronostic. En outre, si l'évolution clinique est favorable avec réossific ation et disparition des lésions, ceci ne permet pas de parler de guérison. Des cas de rechutes ou de reprises évolutives, même après des périodes de rémission de plusieurs années, ont pu être observés.

\section{CONCLUSION}

Depuis son identification par Lichtenstein en 1953 [1], I'histiocytose X a fait l'objet de nombreuses publications. On sait maintenant qu'il s'agit d'une maladie polymorphe recouvrant des tableaux cliniques très divers, allant de formes bénignes localisées (granulome éosinophile) à des formes généralisées beaucoup plus sévères (maladie de Abt-Letterer-Siwe) qui ressemblent beaucoup à une affection maligne. L'évolution des moyens diagnostiques a permis de rattacher à I'histiocytose $X$ des tableaux cliniques ne correspondant à aucune des trois formes classiques décrites.

Si les signes cliniques, et notamment ceux des localisations buccales, sont maintenant bien connus, le diagnostic d'histiocytose $X$ repose sur l'examen anatomopathologique. La mise en évidence dans les lésions, quel que soit le cadre clinique dans lequel elles s'inscrivent, d'une prolifération histiocytaire et/ou, dans les cellules histiocytaires, d'éléments ultrastructuraux caractéristiques ou corps de Birbeck, suffisent pour assurer le diagnostic de cette affection.

D'étiologie encore inconnue, les progrès apportés par la microscopie électronique et l'immunohistochimie ont permis une meilleure compréhension de l'étiopathogénie de l'histiocytose $X$. Il existe une identité entre les cellules histiocytaires retrouvées dans les lésions de l'histiocytose $X$ et les cellules de Langerhans. Ainsi, au terme d'histiocytose $X$ considéré comme trop général, on substitue peu à peu celui d'histiocytose à cellules de Langerhans. En l'absence d'étiopathogénie précise, le traitement de cette maladie reste empirique : en général et de façon schématique, on opte pour une exérèse chirurgicale dans les formes localisées et une chimiothérapie dans les formes dissémi- médecin€ buccale chirurgie buccale VOL. $11, \mathrm{~N}$ 2005 page 171 
nées. Dans les cas simples et limités, la chirurgie constitue le traitement de première intention. Le plus souvent, c'est un spécialiste en chirurgie maxillo-faciale, en collaboration avec un cancérologue qui, après la réalisation d'un bilan complet, prend la responsabilité du traitement.

Enfin, comme cela ressort des deux observations cliniques rapportées, l'histiocytose avec son important potentiel de diffusion, et surtout son caractère imprévisible, a une évolution qui n'est pas toujours contrôlable, ce qui interdit tout pronostic à long terme.

Dans ce contexte, c'est plus l'exactitude du diagnostic que sa précocité qui peut influencer le pronostic de cette affection. La révélation de cette maladie se faisant très fréquemment par des manifestations buccales, on ne saurait trop insister sur l'importance du rôle de l'odontologiste pour son diagnostic et pour sa prise en charge (réhabilitation prothétique et surveillance) de ces patients. médecine buccale chirurgie buccale

L. $11, \mathrm{~N}^{\circ} 3$ 2005

page 172

\section{RÉFÉRENCES}

1 - Lichtenstein L, Histiocytosis X. Integration of eosinophilic granuloma of bone, «Abt-Letterer-Siwe Disease » and «Hand-Schüller-Christian disease » as related manifestations of a single nosologic entity. Arch Pathol 1953; $56: 84-102$.

2 - Nezelof C, Basset F, Rousseau F. Histiocytosis X. Histogenetic arguments for a Langerhans cell origine. Biomedicine $1973 ; 18: 365-71$.

3 - Risdall RJ, Dahner LP, Duray T, Kobrinsky N, Robinson L, Nesbit ME. Histocytosis-X (Langerhans cell histiocytosis): prognostic role of histopathology. Arch Pathol Lab Med 1983 ; 107 : 59-63.

4 - HAND A J R. Polyuria and tuberculosis. Arch Pediatr $1893 ; 10: 673-5$.

5 - SCHÜLLER A. Über eigenartige Schädeldefekte im J ugendalter. Forts chritte Röntgenstrahlen 1915-1916 ; 23: 12 .

6 - Christian HA. Defects in membranous bones, exophtalmos and diabetes insipidus, an unusual syndrome of dyspituitarism: a clinical study. Med Clin North Am $1920 ; 3: 849$.

7 - Letterer E. Aleukämische Reticulose. Frankfurt Z Pathol $1924 ; 30: 377-94$.

8 - SIWE SA. Die reticuloendotheliose: ein neues Krankheitsbild unter den hepatosplenomegalien. Kinderheilkunde $1933 ; 55$ : 212-47.

9 - Broadbent V, Egeler RM, Nesbit ME J R. Langerhans' cell histiocytosis - clinical and epidemiologic aspects. BrJ Cancer $1994 ; 23: 11-6$.

10-Chomette G, Auriol M, Ragot JP, Guilbert F. Histiocytose $X$ des maxillaires : étude anatomo-clinique à propos de 61 cas. Rev Stomatol Chir Maxillofac 1987 ; $88: 334-44$.

11 - BensGhiR R. Contribution à l'étude de l'histiocytose X chez l'enfant à propos de deux cas. Thèse $n^{\circ} 5$, Faculté de médecine de Rabat, Maroc, 1994.

12 - HaRTMAN KS. Histiocytosis X. A review of 114 cases with oral involvement. Oral Surg Oral Med Oral Pathol $1980 ; 49: 38-54$.
13 - Bollini G, J ouve L, Genet J C, Jacquemier M, BouYALA J M. Bone lesions in histiocytosis X.J Pediatr Orthop $1991 ; 11: 469-77$.

14 - Benjelloun A, Essakalli l, Alaoui-Rachidi F, Amarti A, BenchaqRoun L, KZADRI M. Histiocytose X à localisation mandibulaire. A propos d'un cas. Rev Stomatol Chir Maxillofac $1997 ; 98: 31-6$.

15 - Dagenais M, Pharoah MJ , SiKorski PA. The radiographic characteristics of histiocytosis $X$. Oral Surg Oral Med Oral Pathol $1992 ; 74: 230-6$.

16 - SCHAJ OWICZ F, SCHULLITEL J . Eosinophilic granuloma of the bone and its relationship to Hand-Schüller-Christian and Abt-Letterer-Siwe syndromes. J Bone J oint Surg $1973 ; 55 B: 545-65$.

17 - Nauert C, Zornova J, Ayala A, Harle TS. Eosinophilic granuloma of the bone: diagnosis and management. Skeletal Radiol $1983 ; 10: 227-35$.

18 - OSCHNER SF. Eosinophilic granuloma of the bone: experience with 20 cases. Am J Roentgenol Radium Ther Nuclear Med $1966 ; 97: 719-26$.

19 - Ardekian L, Peled M, Rosen D, Rachmiel A, El-Naj IA, LAUfER D. Clinical and radiographic features of eosinophilic granuloma of the jaws. Oral Surg Oral Med Oral Pathol Oral Radiol Endod 1999 ; 87 : 238-42.

20 - RegezI J SCIUBba J . Oral pathology: clinical pathologic correlations, 2nd ed, WB Saunders Philadelphia, 1993 : 413-6.

21 - ARTZI Z, Grosky M, Raviv M. Periodontal manifestations of adult onset of histiocytosis X.J Periodontol 1989 ; $60: 57-66$.

22 - Holzhauer AM, Abdelsayed RA, Sutley SH.Eosinophilic granuloma. A case report with pathologic fracture. Oral Surg Oral Med Oral Pathol Oral Radiol Endod 1999 ; $87: 756-9$.

23 - Snyder SR, Merkow LP, White NS. Eosinophilic granuloma of bone: report of case. J Oral Surg 1973; 31 : 712-5.

24 - STORRS J . Bilateral eosinophilic granuloma of the mandible. Oral Surg Oral Med Oral Pathol $1976 ; 41$ : 93-100. 
25 - Watzke IM, Millesi W, Kermer C, Gisslinger H. Multifocal eosinophilic granuloma of the jaw: long term follow-up of a novel intraosseous corticoid treatment for rec alcitrant lesions. O ral Surg Oral Med Oral Pathol Oral Radiol Endod $2000 ; 90: 317-22$.

26 - Guilbert F, Chomette G, Le Charpentier Y, Auriol M. XXXIIIle Congrès de Stomatologie et de $C$ hirurgie maxillofaciale et plastique de la face. Les tumeurs bénignes et les pseudo-tumeurs des maxillaires. Rev Stomatol Chir Maxillofac $1993 ; 94:$ 197-265.

27 - Chomette G, Guilbert F. Tumeurs bénignes et pseudotumeurs des maxillaires d'orig ine non dentaire (12p). Encycl Med Chir Odonto-Stomatol, Elsevier Paris. $22062 \mathrm{H10}, 1986$.

28 - Dadoune J P, Hadj isky P, Siffrol J P, Vendrely E. Histologie $2^{e}$ éd. (p 271) Médecine-Sciences, Flammarion Paris $2000: 271$.

29 - Birbeck MD, Breathnach A, Everall J D. An electron microscope study of basal melanocytes and high level clear cells (Langerhans cells) in vitiligo. J Invest Dermatol $1961 ; 37: 51-64$

30 - Basset F, Nezelof C, Turiaf MJ . Présence en microscopie électronique de structures filamenteuses originales dans les lésions pulmonaires et osseuses de I'histiocytose $X$; état actuel de la question. Bull Soc Med Hop (Paris) 1966 ; 117 : 413-26.

31 - Barticick A, Friedrich Re, Roeser K, Schmelzle R.Oral Langerhans cell histiocytosis. J Craniomaxillofac Surg 2002; $30: 91-6$

32 - J ouve L, Bollini G, J acquemier M, Bouyala J M. 15 cases of vertebral involvement of histiocytosis $X$ in children. Review of the literature. Ann Pedriatr (Paris) 1991; 38 : 167-74.
33 - Ladisch S, Gadner H, Arico M, Broadbent V, Grois N, J ACOBSON A, KOMP D, NICHOLSON HS. LCH-I: a randomized trial of etoposide vs. vinblas tine in disseminated Langerhans cell histiocytosis. The Histiocyte Society. Med Pediatr Oncol $1994 ; 23$ : 107-10.

34 - Gadner H, Grois N, Arico M, Broadbent V, CeciA, J AKObSON A, Komp D, Michaelis J, Nicholson S, POTSCHGER U, PRITCHARD J , LADISCH S. A randomized trial of treatment for multisystem Langerhans' cell histiocytosis. The Histiocyte Society. J Pediatr 2001 ; 138 : 728-34.

35 - Osband Me, Lipton J M, Lavin P, Levey R, Vanter G, Greenberger J S, Mc Caffrey RP, Parkman R. Histiocytosis $X$ : Demonstration of abnormal immunity, T-cell histamine $\mathrm{H} 2$-receptor deficiency and successful treatment with thymic extract. N EnglJ Med 1981 ; 304 : 146-53.

NDLR : depuis la rédaction de cet article, deux artic les traitant ce sujet sont parus :

Key S, O'Brien C.J , Silvester KC, Crean SJ . Eosinophilic granuloma: resolution of maxillofacial bony lesions following minimal intervention. Report ot three cases and review of the literature. J Cranio-Maxillofac Surg 2004 ; 32 : 170-5.

Scolozzi P, Lombardi T, Monnier P, J aques B. Multisystem Langerhans' cell histocytosis (Hand-Schüller-Christian disease) in an adult: a case report and review of the literature. Eur Arch Otorhinolaryngol 2004 ; 261 : 326-30. médecinє buccale chirurgie buccale VOL. $11, \mathrm{~N}$ 2005

page 173 